\title{
Effect of Lipopolysaccharide on Global Gene Expression in the Immature Rat Brain
}

\author{
SASKIA EKLIND, HENRIK HAGBERG, XIAOYANG WANG, KARIN SÄVMAN, ANNA-LENA LEVERIN, MAJ HEDTJÄRN, AND \\ CARINA MALLARD
}

\begin{abstract}
Department of Obstetrics and Gynecology [S.E., H.H.], Institute for the Health of Women and Children, Departments of Neuroscience and Physiology [S.E., X.W., A.-L.L., M.H., C.M.] and Pediatrics [K.S.], Perinatal Center, Sahlgrenska Academy, Göteborg University, 40530

Göteborg, Sweden
\end{abstract}

\begin{abstract}
To improve the understanding of the molecular mechanisms whereby lipopolysaccharide (LPS) affects the immature brain, global gene expression following LPS exposure was investigated in neonatal rats. Brains ( $n=5 /$ time point) were sampled 2,6 , and $72 \mathrm{~h}$ after LPS and compared with age-matched controls. The mRNA from each brain was analyzed separately on Affymextrix GeneChip Rat Expression Set 230. The number of genes regulated after LPS were 847 at 2 h, 1564 at $6 \mathrm{~h}$, and 1546 genes at $72 \mathrm{~h}$. Gene ontology analysis demonstrated that, at both 2 and $6 \mathrm{~h}$ after LPS, genes associated with protein metabolism, response to external stimuli and stress (immune and inflammatory response, chemotaxis) and cell death were overrepresented. At $72 \mathrm{~h}$, the most strongly regulated genes belonged to secretion of neurotransmitters, transport, synaptic transmission, cell migration, and neurogenesis. Several pathways associated with cell death/survival were identified (caspase-tumor necrosis factor $\alpha$ [TNF- $\alpha]-$, p53-, and Akt/phosphatidylinositol-3kinase (PI3 K)-dependent mechanisms). Caspase-3 activity increased and phosphorylation of Akt decreased $8 \mathrm{~h}$ after peripheral LPS exposure. These results show a complex cerebral response to peripheral LPS exposure. In addition to the inflammatory response, a significant number of cell death-associated genes were identified, which may contribute to increased vulnerability of the immature brain to hypoxia-ischemia (HI) following LPS exposure. (Pediatr Res 60: 161-168, 2006)
\end{abstract}

$I^{\prime}$ nflammatory processes are recognized key mediators of perinatal brain injury and intrauterine infection/inflammation is associated with an increased risk of cerebral white matter damage and subsequent cerebral palsy in the offspring. A number of experimental studies have shown that exposure to LPS during pregnancy induces cerebral white matter injury in the fetus or newborn animal (1-3). In addition, epidemiologic evidence suggests that a combination of adverse factors may have additive effects and further increase the risk of cerebral palsy in children. In particular, it was shown that

Received February 1, 2006; accepted April 2, 2006.

Correspondence: Carina Mallard, Ph.D., Perinatal Center, Department of Neuroscience and Physiology, Sahlgrenska Academy, Göteborg University, Box 432, 40530 Göteborg, Sweden; e-mail: carina.mallard@fysiologi.gu.se

This work was supported by the Swedish Medical Research Council (K2004-33X14185-03A and K2004-33X-09455), the Åhlén Foundation, the Sven Jerring Foundation, the Magnus Bergvall Foundation, the Wilhelm and Martina Lundgren Foundation, the Linnéa and Josef Carlsson Foundation, the Frimurare Barnhus Foundation, the Göteborg Medical Society, and the Åke Wibergs Foundation and by grants to researchers in the public health service from the Swedish government (ALF).

DOI: 10.1203/01.pdr.0000228323.32445.7d infection during pregnancy in combination with potentially asphyxiating conditions at birth markedly increased the risk of spastic cerebral palsy in infants of normal birth weight (4). Studies in neonatal rats support these findings, and we and others have demonstrated that peripherally administered LPS aggravates HI brain injury $(5,6)$. These studies suggest that LPS induces mediators in the brain that by themselves may be damaging or primes the brain to become more sensitive to later events. We have previously shown that the sensitizing effect of LPS on HI does not relate to alterations in cerebral blood flow or temperature (5), whereas LPS-induced tolerance is associated with the induction of glucocorticoids (7).

Systemically administered LPS induces complex biochemical alterations in the adult CNS; however, much less is known of the response in the immature brain, and evidence suggests that the immature brain may be more susceptible to inflammatory mediators than the adult brain (8). Maternally administered LPS induces increased expression of interleukin (IL) $-1 \beta$ and TNF- $\alpha$ mRNA in the fetal brain (1). We have demonstrated regulation of the LPS receptors toll-like receptor 4 (TLR-4) and CD14 in the neonatal brain after LPS exposure (5). However, very little is known of the global changes in the immature brain following a systemic endotoxin challenge.

A relatively new approach to examine global changes in gene expression is the use of microarrays, with analysis of several thousands of transcripts in a single sample. We have previously shown a very good correlation between this method and more conventional reverse transcriptase polymerase chain reaction (PCR) techniques $(9,10)$. One study, using microarray technology, examined the short-term gene expression in the hypothalamus of adult mice after LPS exposure (11). However, there are no studies investigating the global gene expression in the immature brain following LPS expo-

\footnotetext{
Abbreviations: FAIM2, fas apoptotic inhibitory molecule 2; HI, hypoxiaischemia; LPS, lipopolysaccharide; NF- $\boldsymbol{\kappa} \mathbf{B}$, nuclear factor- $\boldsymbol{\kappa}$; pAkt, phosphorylated Akt; PHLDA1, pleckstrin homology-like domain, member 1; PI3 $\mathbf{K}$, phosphatidylinositol-3-kinase; PKB, protein kinase B; PND, postnatal day; RMA, robust multiarray average
} 
sure. The purpose of this study was therefore to characterize the global gene expression following exposure to LPS in a rat model approximately equivalent to a term baby. The specific aim was to identify genes that may be involved in inflammatory and cell death mechanisms in the brain because we hypothesized that these will be important and could contribute to increased sensitivity to further insults.

\section{MATERIALS AND METHODS}

Animal studies. Wistar rat pups from Mollegaard Breeding and Research Centre A/S, Skensved, Denmark were used in all experiments. The Animal Ethics Committee of the University of Göteborg approved all experiments. Animals from each litter were randomly assigned to the different groups below. LPS (0.3 mg/kg, Sigma Chemical Co. LPS O55:B5 in 0.9\% NaCl, i.p.) was given to rat pups at postnatal day (PND) seven.

Gene analysis. LPS-treated pups ( $n=5 /$ time point) were killed 2, 6 , and $72 \mathrm{~h}$ after the injection. Naïve control rats were killed at postnatal day (PND) $7(n=5)$ and PND $10(n=5)$. Animals were decapitated, and the brains, excluding the brainstem and cerebellum, were quickly removed and frozen on dry ice. Five micrograms of total RNA was extracted using Rneasy Mini Kit (Qiagen Inc.)

The mRNA from each brain was analyzed separately on Affymextrix GeneChip Rat Expression Set 230, which contains probe sets for detection of 15.923 transcripts (Swegene, Lund, Sweden). Data processing was performed on Affymetrix .CEL files using the robust multiarray average (RMA) algorithm (12), which performs three distinct operations: global background normalization, across-array normalization, and $\log _{2}$ transformation of perfect match values (http://stat-www.berkeley.edu/users/bolstad/RMAExpress/ RMAExpress.html). All 25 arrays were normalized together as one experiment to reduce nonbiological variability. The RMA analysis, data management, statistical analysis, and gene ontology were performed using the Web-based GeneSifter software (http://login.genesifter.net/). In addition to PubMed (http://www.ncbi.nlm.nih.gov/entrez/query.fcgi?CMD = search\&DB = pubmed), the database http://genome-www5.stanford.edu/cgi$\mathrm{bin} /$ source/sourceSearch was used to obtain information about specific genes of interest.

Real-time PCR (RT-PCR). To confirm the microarray results, RT-PCR (Light Cycler, Roche) was performed on three selected genes $6 \mathrm{~h}$ after LPS administration. First-strand cDNA synthesis was performed using Superscript RNase $\mathrm{H}^{-}$reverse transcriptase kit (Life Technologies, Inc.), random hexamer primers, and dNTP (dATP, dCTP, dGTP, and dTTP; Roche Molecular Biochemicals) from the same total RNA that had been used for microarray analysis.

Each PCR $(20 \mu \mathrm{L})$ contained $1 / 80$ cDNA, 2 or $3 \mu \mathrm{M} \mathrm{MgCl}_{2}$ depending on the optimal concentration for each primer pair, $0.5 \mu \mathrm{M}$ forward and reverse primers, and $2 \mu \mathrm{L}$ of LightCycler-FastStart DNA Master SYBR Green I (Roche). Following primer pairs (CyberGene AB, Sweden), annealing temperatures and elongation times were used; metallothionein forward $5^{\prime}$ GCCTTCTTGTCGCTTACACC-3' reverse 5'-CAGCAGCACTGTTCGTCACT- $3^{\prime}, 58^{\circ}, 11 \mathrm{~s}$; CD14 forward 5'-CAGGAACTTTGGCTTTGCTC-3' reverse $5^{\prime}$-ACCGATGGACAACTTTCAGG- $3^{\prime}, 58^{\circ}, 10$ s and interferon induced transmembrane protein 2 forward $5^{\prime}$-CTCTACCTTTCGCTGCTGCT-3' reverse 5'-GAACAGGGACCAGACCACAT-3', 56 ${ }^{\circ}$, 9s. Each sample from the individual animal was assayed in duplicate. Melting curves were performed to check that only one product had been produced. A standard curve was generated to every gene for quantification and estimating amplification efficiency using decreasing concentrations of cDNA. Transcripts were quantified with the relative standard curve and related against the housekeeping gene glyceraldehyde-3-phosphate dehydrogenase.

Sample preparation for caspase-3-like analysis and Western blot. Pups were deeply anesthetized (thiopental, i.p.) and perfused intracardially with $0.9 \% \mathrm{NaCl}$ at $2 \mathrm{~h}(n=7), 8 \mathrm{~h}(n=7)$, and $72 \mathrm{~h}(n=8)$ after LPS and control animals at PND $7(n=8)$ and PND $10(n=8)$. The brains were rapidly dissected and quickly frozen. One hemisphere from each animal was sonicated in ice-cold homogenization buffer $(50 \mathrm{mM}$ Tris, $\mathrm{pH} 7.3,5 \mathrm{mM}$ ethylenediamine tetraacetic acid (EDTA), $1 \%$ protease inhibitor cocktail (P8340; Sigma Chemical Co.)). The protein concentration was determined according to Whitaker and Granum adapted for microplates (13).

Fluorometric assay of caspase-3-like activity. Samples, $25 \mu \mathrm{L}$, were added to a microplate and mixed with $75 \mu \mathrm{L}$ extraction buffer $(50 \mathrm{mM}$ Tris, pH 7.3; $100 \mathrm{mM} \mathrm{NaCl} ; 5 \mathrm{mM}$ EDTA; $1 \mathrm{mM}$ ethyleneglycol-bis- $(\beta-$ aminoethylether)- $\mathrm{N}, \mathrm{N}, \mathrm{N}^{\prime}, \mathrm{N}^{\prime}$-tetraacetic acid (EGTA); $0.2 \% 3-[(3-$ cholamidoprophylene) dimethylamonio]propane sulfonic acid; $1 \%$ protease inhibitor cocktail (P8340; Sigma Chemical Co.), 1 mM phenylmethylsulfonylfluoride. After incubation for $15 \mathrm{~min}$ at room temperature, $100 \mu \mathrm{L}$ peptide substrate, $25 \mu \mathrm{M}$ Ac-Asp-Glu-Val-Asp-aminomethyl coumarin (Ac-DEVDAMC; Enzyme Systems Products, Livermore, CA) in assay buffer (50 mM Tris-HCl, pH 7.3; $100 \mathrm{mM} \mathrm{NaCl} ; 5 \mathrm{mM}$ EDTA; $1 \mathrm{mM}$ EGTA; $1 \mathrm{mM}$ phenylmethylsulfonylfluoride, $10 \mathrm{mM}$ dithiothreitol was added to the samples. Cleavage of the substrate was measured at $37^{\circ} \mathrm{C}$ using Spectramax Gemini microplate fluorometer (Molecular Devices, Sunnyvale, CA), with an excitation wavelength of $380 \mathrm{~nm}$ and emission wavelength of $460 \mathrm{~nm}$. The degradation was followed at 2-min intervals for $2 \mathrm{~h}$, and $\mathrm{V}_{\max }$ was calculated from the entire linear part of the curve. Standard curves with AMC in the appropriate buffer were used to express the data in picomoles of AMC (7-amino-4-methyl-coumarin) formed per minute and per milligram of protein.

Western blot. Samples, $25 \mu \mathrm{g}$ protein, were prepared as recommended by the manufacturer (Novex, San Diego, CA) and electrophoresed on NuPAGE Novex 4-12\% Bis-Tris Gels (Novex, San Diego, CA). After electrophoresis, proteins were transferred to a nitrocellulose membrane (Optitran, $0.2 \mu \mathrm{m}$; Schleicher \& Schuell, Inc., Dassel, Germany). Membranes were blocked in blocking buffer (30 mM Tris-HCl, $\mathrm{pH} 7.5 ; 100 \mathrm{mM} \mathrm{NaCl}$; and $0.1 \%$ Tween 20 (TBS-T) containing 5\% fat-free milk powder). After TBS-T washing, membranes were incubated with the following primary antibodies, diluted in TBS-T containing $3 \%$ bovine serum albumin and $9 \mathrm{mM} \mathrm{NaN}_{3}$ overnight at $8^{\circ} \mathrm{C}$ : anti-phospho-Akt $\left(\mathrm{Ser}^{473}\right)$, \#9271) rabbit polyclonal 1:2000 or anti-Akt (\#9272) rabbit polyclonal 1:2000 (Cell Signaling Technology, Inc., Beverly, MA). Blots were washed three times with TBS-T and incubated with goat anti-rabbit peroxidase-conjugated secondary antibody (Vector Laboratories, Inc. Burlingame, CA) diluted in blocking buffer. Immunoreactive species were visualized using Super Signal Western Dura chemiluminescence substrates (Pierce Biotechnology, Inc., Rockford, IL) and a cooled CCD camera (LAS1000; Fuji Photo Film Co., Ltd., Tokyo, Japan). Immunoreactive bands were quantified using Image Gauge software (version 3.3, Fuji). To standardize quantification between the gels, five controls from PND 8 samples were run on every gel. Membranes were stripped for reprobing with new antibody by incubating them in stripping buffer $(62.5 \mathrm{mM}$ Tris-HCl, $\mathrm{pH} 6.7,100 \mathrm{mM}$ $\beta$-mercaptoethanol, and $2 \% \mathrm{SDS}$ ) at $50^{\circ} \mathrm{C}$ for $30 \mathrm{~min}$.

Statistical analysis. Pairwise $t$ test analysis with Benjamin Hochberg correction, the false detection rate set at 0.05 , and a threshold of 1.2-fold change was applied to microarray data to determine significantly regulated genes. Time points 2 and $6 \mathrm{~h}$ were compared with PND 7 controls. The 72-h LPS animals were compared with age-matched PND 10 control pups. Gene ontology analysis was applied to genes that were found to be significantly regulated. Gene ontologies that included $\geq 10$ genes are presented in the results. Caspase- 3 and phosphorylated Akt (pAkt) measurements were compared using the Kruskal-Wallis test followed by Dunn's multiple comparison test and are presented as mean \pm SEM.

\section{RESULTS}

Global gene changes. The number of genes regulated after LPS were 847 at $2 \mathrm{~h}, 1564$ at $6 \mathrm{~h}$, and 1546 at $72 \mathrm{~h}$. At all time points, the majority of genes were down-regulated. At $2 \mathrm{~h}$ after LPS, 187 genes were up-regulated and 660 downregulated, at 6 h 578 genes were up-regulated and 986 downregulated and at $72 \mathrm{~h}$ there were 656 genes up-regulated and 890 down-regulated.

The gene ontology analysis revealed that at $2 \mathrm{~h}$ after LPS administration, categories of protein modification and folding, immune and inflammatory response, response to chemical substance, chemotaxis, and programmed cell death were overrepresented (Table 1). There was also an overrepresentation of cellular processes, including cell-cell signaling, cell adhesion, and regulation of cell proliferation and differentiation. As shown in Table 2, at $6 \mathrm{~h}$, gene ontologies associated with metabolism remained regulated. Furthermore, genes in the category of response to external stimuli and stress stayed highly overrepresented (immune, inflammatory, humoral immune response, cellular defense response, response to chemical substance and chemotaxis). Cell death continued to be overrepresented, as well as cell proliferation, cell organization 
Table 1. Gene ontologies regulated at 2 h after LPS compared to PND 7 control pups

\begin{tabular}{|c|c|c|c|c|c|c|}
\hline Ontology & No. of reg. genes & No. of up-reg. & No. of down-reg. & No. of genes on array & $\mathrm{Z}$ score up & $\mathrm{Z}$ score down \\
\hline \multicolumn{7}{|l|}{ Physiological processes } \\
\hline \multicolumn{7}{|l|}{ Metabolism } \\
\hline Protein & 125 & 28 & 97 & 1446 & 0.67 & 4.92 \\
\hline Modification & 70 & 14 & 56 & 720 & 0.46 & 4.71 \\
\hline Folding & 12 & 2 & 10 & 117 & -0.02 & 2.20 \\
\hline Nucleobase, nucleotide, etc. & 74 & 16 & 58 & 1186 & -1.15 & 0.90 \\
\hline Biosynthesis & 45 & 14 & 31 & 654 & 0.84 & 0.44 \\
\hline Phosphorous & 35 & 8 & 27 & 452 & 0.06 & 1.69 \\
\hline Catabolism & 29 & 7 & 22 & 525 & -0.74 & -0.26 \\
\hline Lipid & 16 & 4 & 12 & 371 & -1.00 & -1.14 \\
\hline Organic acid & 13 & 4 & 9 & 298 & -0.53 & -1.20 \\
\hline \multicolumn{7}{|l|}{ Response to external stimuli and stress } \\
\hline Biotic & 38 & 29 & 9 & 481 & 7.53 & -2.83 \\
\hline Immune response & 32 & 25 & 7 & 349 & 8.01 & -2.26 \\
\hline Wounding & 24 & 18 & 6 & 205 & 7.86 & -1.05 \\
\hline Inflammatory response & 17 & 15 & 2 & 126 & 8.84 & -1.56 \\
\hline Abiotic & 14 & 10 & 4 & 262 & 2.64 & -2.33 \\
\hline Response to chemical substance & 10 & 9 & 1 & 153 & 3.98 & -2.29 \\
\hline Chemotaxis & 10 & 9 & 1 & 74 & 6.91 & -1.29 \\
\hline \multicolumn{7}{|l|}{ Death } \\
\hline Programmed cell death & 36 & 16 & 20 & 327 & 4.50 & 1.55 \\
\hline \multicolumn{7}{|l|}{ Cellular processes } \\
\hline \multicolumn{7}{|l|}{ Cell growth and/or maintenance } \\
\hline Transport & 81 & 16 & 65 & 1308 & -1.62 & 1.12 \\
\hline Cell proliferation & 41 & 14 & 27 & 572 & 1.37 & 0.38 \\
\hline Cell organization and biogenesis & 37 & 7 & 30 & 502 & -0.61 & 1.79 \\
\hline \multicolumn{7}{|l|}{ Cell communication } \\
\hline Signal transduction & 91 & 30 & 61 & 1372 & 1.46 & 0.08 \\
\hline Cell-cell signaling & 35 & 6 & 29 & 414 & -0.46 & 2.67 \\
\hline Transmission of nerve impulse & 24 & 0 & 24 & 258 & -2.18 & 3.92 \\
\hline Cell adhesion & 24 & 11 & 13 & 328 & 2.31 & -0.41 \\
\hline Cell-cell adhesion & 10 & 5 & 5 & 94 & 2.68 & 0.43 \\
\hline \multicolumn{7}{|l|}{ Regulation of cellular processes } \\
\hline Regulation of cell proliferation & 18 & 8 & 10 & 208 & 2.37 & 0.28 \\
\hline Cell differentiation & 20 & 10 & 10 & 245 & 2.87 & -0.26 \\
\hline Cell motility & 16 & 7 & 9 & 247 & 1.35 & -0.60 \\
\hline \multicolumn{7}{|l|}{ Development } \\
\hline \multicolumn{7}{|l|}{ Morphogenesis } \\
\hline Organogenesis & 47 & 15 & 32 & 799 & 0.33 & -0.60 \\
\hline
\end{tabular}

For each ontology, the total number of regulated (reg.) genes, the number of up-regulated (up-reg.) and down-regulated (down-reg.) genes, the total number of genes on the array and the $Z$ score are presented. $Z$ scores that are $>2.0$ or $>-2.0$ are shown in bold. Analysis: pairwise analysis with Benjamin Hochberg correction set at 0.05 and fold change set at 1.2 . Only regulated ontologies containing $\geq 10$ genes are shown.

and biogenesis, cell growth, and signal transduction. Although several categories associated with metabolism were still regulated at $72 \mathrm{~h}$ after LPS administration, there was a smaller response in genes belonging to response to external stimuli, stress, and cell death (Table 3). The most highly regulated genes, $72 \mathrm{~h}$ after LPS, were found in the ontology secretions of neurotransmitter, cellular transport, ribosome biogenesis and assembly, synaptic transmission, cell migration, and neurogenesis, all which had $Z$ scores $>4$.

Inflammation-related genes. There was a strong proinflammatory response in the brain 2 and $6 \mathrm{~h}$ after LPS, including up-regulation of $\alpha$ - and $\beta$ - chemokines and pro- and antiinflammatory cytokine genes (Table 4 , Web based). Genes associated with immune cell activity were up-regulated including major histocompatibility complex $(\mathrm{MCH})$ class I and II receptor-related genes, lymphocyte, macrophage, and cell adhesion protein-associated transcripts (Table 5, Web based).
Cell death-related genes. A significant number of regulated genes belonged to pro- and antiapoptotic pathways [caspase-3, transglutaminase 2, Nur77, inhibitor of apoptosis protein 1 (IAP 1), baculoviral IAP repeat-containing 2 (IAP 2), growth arrest and DNA damage-inducible gene beta, bcl2-associated athanogene 3, GTP cyclohydrolase 1, receptor-interacting serine-threonine kinase 3, myeloid cell leukemia sequence 1], including p53-dependent factors [IGF binding protein 3 (IGFBP3), Notch gene homology-like domain, member 1 and $\mathrm{BH} 3$ interacting domain death agonist] (Table 6, Web based). Several of the genes also belonged to Akt/ phosphatidylinositol-3-kinase (Akt/PI3 K) cell survival mechanisms, such as serum/glucocorticoid-regulated kinase (SGRK), pleckstrin homology-like domain, member 1 (PHLDA1), phosphatase and tensin homolog (PTEN), guanine nucleotide binding protein (GNBP), fas apoptotic inhibitory molecule 2 (FAIM2), and tax 1 binding protein 1 (TAX1BP1). 
Table 2. Gene ontologies regulated at 6 h after LPS compared to PND 7 control rats

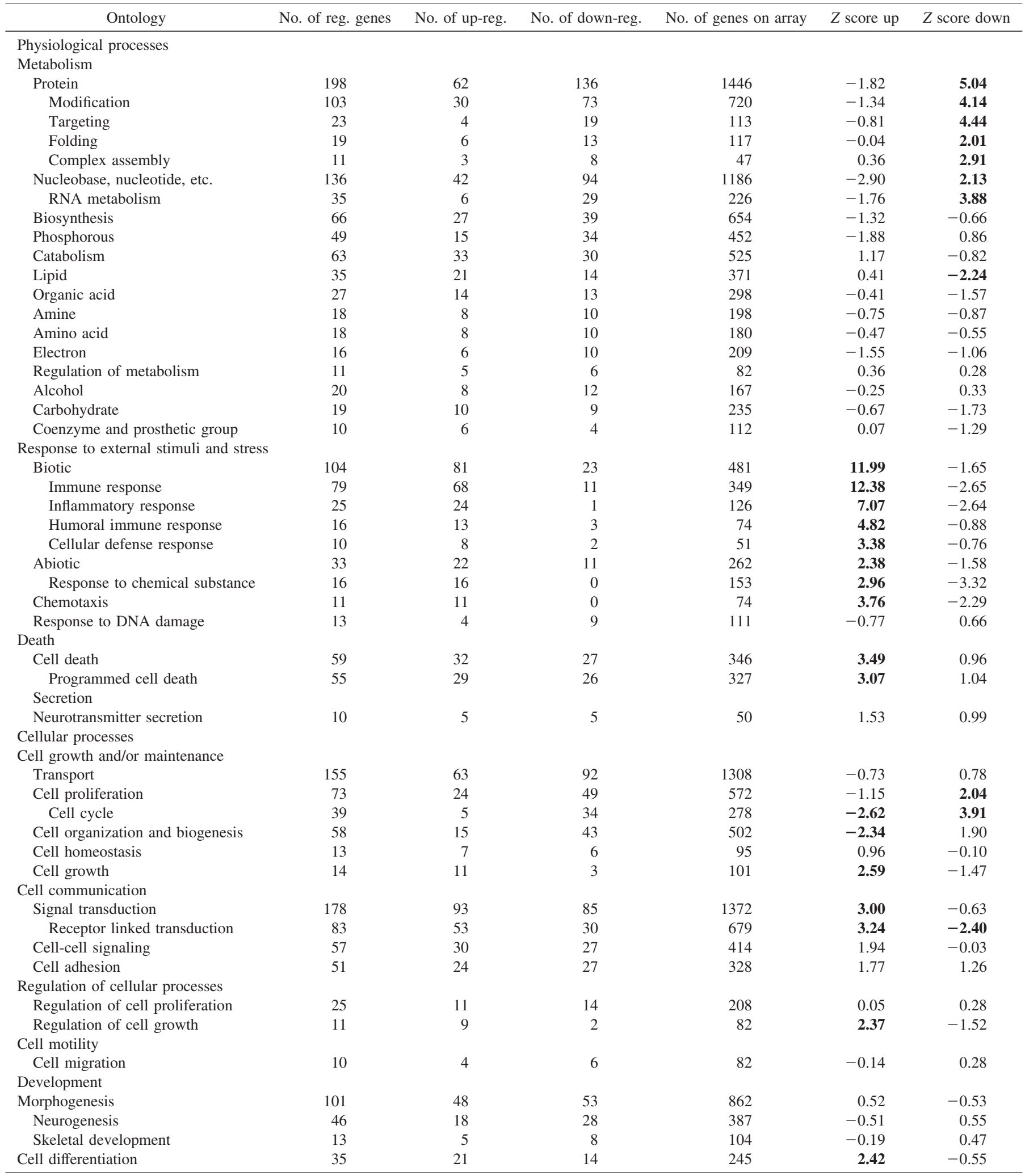

For each ontology, the total number of regulated (reg.) genes, the number of up-regulated (up-reg.) and down-regulated (down-reg.) genes, the total number of genes on the array, and the $Z$ score is presented. $Z$ scores that are $>2.0$ or $>-2.0$ are shown in bold. Analysis: pairwise analysis with Benjamin Hochberg correction set at 0.05 and fold change set at 1.2 . Only regulated ontologies containing $\geq 10$ genes are shown.

Caspase-3 activity and phosphorylation of Akt. To support the mRNA findings of the LPS effects on cell death/survival pathways, we examined the caspase-3 and Akt activation following LPS exposure. Activity measurements demonstrated an increase in caspase-3 activity and Western blot analysis showed a decrease in pAkt at $8 \mathrm{~h}$ after LPS (Fig. 1). 
Table 3. Gene ontologies regulated at $72 \mathrm{~h}$ after LPS compared to PND 10 control rat pups

\begin{tabular}{|c|c|c|c|c|c|c|}
\hline Ontology & No. of reg. genes & No. of up-reg. & No. of down-reg. & No. of genes on array & $\mathrm{Z}$ score up & Z score down \\
\hline \multicolumn{7}{|l|}{ Physiological processes } \\
\hline \multicolumn{7}{|l|}{ Metabolism } \\
\hline Protein & 201 & 93 & 108 & 1446 & 3.80 & -1.19 \\
\hline Biosynthesis & 36 & 21 & 15 & 288 & 2.22 & -1.90 \\
\hline Targeting & 20 & 11 & 9 & 113 & 2.62 & -0.10 \\
\hline Nucleobase, nucleotide, etc. & 132 & 45 & 87 & 1186 & -1.52 & -1.23 \\
\hline Lipid & 32 & 11 & 21 & 371 & -1.57 & -1.85 \\
\hline Organic acid & 23 & 10 & 13 & 298 & -1.07 & -2.49 \\
\hline Carboxylic acid metabolism & 23 & 10 & 13 & 296 & -1.04 & -2.46 \\
\hline Amine & 16 & 5 & 11 & 198 & -1.43 & -1.39 \\
\hline Amino acid & 15 & 5 & 10 & 180 & -1.20 & -1.32 \\
\hline Electron & 17 & 8 & 9 & 209 & -0.55 & -2.09 \\
\hline \multicolumn{7}{|l|}{ Response to external stimuli and stress } \\
\hline Biotic & 51 & 26 & 25 & 481 & 0.86 & -2.52 \\
\hline Immune response & 34 & 17 & 17 & 349 & 0.23 & -2.35 \\
\hline Wounding & 22 & 11 & 11 & 205 & 0.52 & -1.51 \\
\hline Abiotic & 37 & 7 & 30 & 262 & -1.54 & 1.95 \\
\hline Perception of external stimuli & 20 & 4 & 16 & 94 & -0.17 & 3.14 \\
\hline Perception of sound & 12 & 2 & 10 & 43 & 0.01 & 3.61 \\
\hline Response to pest/pathogen/parasite & 24 & 12 & 12 & 243 & 0.24 & -1.90 \\
\hline Response to DNA damage & 16 & 8 & 8 & 111 & 1.31 & -0.39 \\
\hline \multicolumn{7}{|l|}{ Death } \\
\hline Cell death & 55 & 21 & 34 & 346 & 1.33 & 1.13 \\
\hline \multicolumn{7}{|l|}{ Secretion } \\
\hline Protein & 54 & 24 & 30 & 314 & 2.63 & 0.89 \\
\hline Vesicle mediated & 53 & 12 & 41 & 276 & -0.22 & 4.12 \\
\hline Side chrome & 35 & 6 & 29 & 169 & -0.67 & 4.30 \\
\hline Organic acid & 16 & 3 & 13 & 55 & 0.30 & 4.19 \\
\hline Neurotransmitter & 14 & 2 & 12 & 41 & 0.08 & 4.93 \\
\hline Amine/polyamine & 13 & 3 & 10 & 44 & 0.70 & 3.52 \\
\hline Cell proliferation & 71 & 25 & 46 & 572 & -0.30 & -0.16 \\
\hline Cell organization and biogenesis & 90 & 34 & 56 & 502 & 2.41 & 2.51 \\
\hline Organelle organization and biogenesis & 56 & 19 & 37 & 303 & 1.41 & 2.60 \\
\hline Ribosome biogenesis and assembly & 14 & 12 & 2 & 65 & 5.35 & -1.52 \\
\hline Cell homeostasis & 13 & 5 & 8 & 95 & 0.30 & 0.07 \\
\hline Cell growth & 10 & 2 & 8 & 101 & -1.27 & -0.11 \\
\hline \multicolumn{7}{|l|}{ Cell communication } \\
\hline Signal transduction & 200 & 74 & 126 & 1372 & 1.57 & 1.50 \\
\hline Intracellular signaling cascade & 99 & 36 & 63 & 553 & 2.23 & 2.87 \\
\hline Receptor linked signal transduction & 95 & 32 & 63 & 679 & 0.13 & 1.08 \\
\hline Cell-cell signaling & 75 & 16 & 59 & 414 & 0.76 & 4.65 \\
\hline Synaptic transmission & 57 & 12 & 45 & 253 & 0.10 & 5.67 \\
\hline Cell adhesion & 57 & 12 & 45 & 328 & -0.85 & 3.74 \\
\hline \multicolumn{7}{|l|}{ Regulation of cellular processes } \\
\hline Regulation of cell proliferation & 21 & 7 & 14 & 208 & -0.88 & -0.79 \\
\hline \multicolumn{7}{|l|}{ Cell differentiation } \\
\hline Regulation of cell differentiation & 12 & 2 & 10 & 76 & -0.83 & 1.58 \\
\hline Neuron differentiation & 11 & 2 & 9 & 47 & -0.12 & 2.74 \\
\hline
\end{tabular}


Table 3. Continued

\begin{tabular}{|c|c|c|c|c|c|c|}
\hline Ontology & No. of reg. genes & No. of up-reg. & No. of down-reg. & No. of genes on array & $Z$ score up & $\mathrm{Z}$ score down \\
\hline Muscle contraction & 13 & 6 & 7 & 104 & 0.56 & -0.56 \\
\hline \multicolumn{7}{|l|}{ Development } \\
\hline \multicolumn{7}{|l|}{ Morphogenesis } \\
\hline Neurogenesis & 68 & 11 & 57 & 387 & -1.72 & 4.83 \\
\hline Cellular morphogenesis & 10 & 2 & 8 & 54 & -0.32 & 1.78 \\
\hline Regulation of biological processes & & & & & & \\
\hline
\end{tabular}

For each ontology, the total number of regulated (reg.) genes, the number of up-regulated (up-reg.) and down-regulated (down-reg.) genes, the total number of genes on the array and the $Z$ score is presented. $Z$ scores that are $>2.0$ or $>-2.0$ are shown in bold. Analysis: pairwise analysis with Benjamin Hochberg correction set at 0.05 and fold change set at 1.2 . Only regulated ontologies containing $\geq 10$ genes are shown.

Figure 1. Caspase 3 and Akt activation. Cerebral caspase-3 like activity (DEVD cleavage) after LPS or vehicle treatment $(A)$. There was increased caspase-3 like activity at $8 \mathrm{~h}$ after LPS compared with PND 7 rats. Phosphorylation of Akt (pAkt) in the brain after LPS or vehicle treatment $(B)$. There was a decrease in pAkt at $8 \mathrm{~h}$ after LPS compared with PND 7 control. Kruskal-Wallis analysis with Dunn's multiple comparison test. $*_{p}<$ 0.05 compared with PND 7 control.

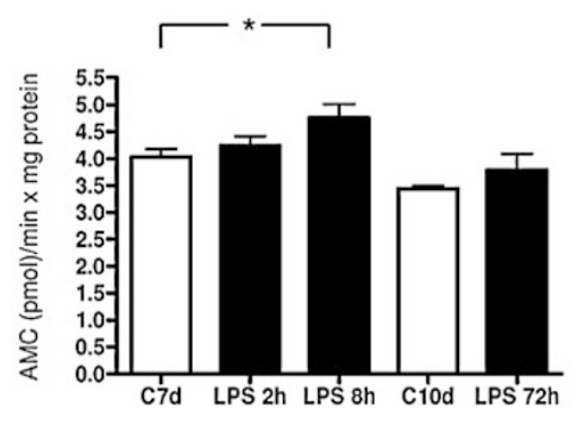

A

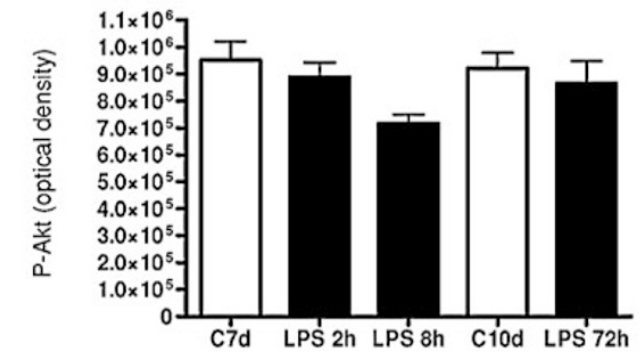

$\boldsymbol{R T}$-PCR. The RT-PCR results demonstrated a good agreement with the microarray data for the metallothionein, interferon-induced transmembrane protein 2 and CD14 genes (Fig. 2).

\section{DISCUSSION}

This is the first study investigating the global gene expression in the neonatal brain following peripheral LPS exposure. As we have previously shown that peripherally administered LPS at low doses aggravates HI brain damage both early (4 h) and at later $(72 \mathrm{~h})$ exposure in the neonatal rat $(5,14)$, it was interesting to identify a large number of genes that are associated with deleterious processes in the brain, such as inflammation and apoptosis. Out of the nearly 16,000 transcripts on the array, $>2000$ genes were regulated during the first $3 \mathrm{~d}$ after LPS exposure. The majority of the most regulated genes belonged to the gene ontology categories of inflammatory responses, cell death, phosphorylation, and ion transport.

Several steps were taken to optimize the analysis; the mRNA from each individual brain was analyzed on a separate chip, which allowed for statistical comparisons including the Benjamin Hochberg correction for multiple comparisons, and all arrays were processed together using the RMA algorithm, which has been suggested to reduce nonbiological variability (12). Furthermore, we used age-matched control animals, which is particularly important when studying the immature brain because a large number of genes are altered due to development.

The early proinflammatory phase following infection, which involves the recruitment and activation of immune cells and their interactions with parenchymal cells, is believed to be detrimental to the brain (15). In support of this, within the first hours of LPS exposure, we found up-regulation of several proinflammatory genes that are known to be involved in the recruitment of immune cells, such as $\alpha$ - and $\beta$-chemokines. Cell adhesion is crucial in recruitment of immune cells and the array analysis revealed that a large proportion of the inflammatory genes were associated with cell adhesion. In addition, several genes associated with stimulated immune cells including macrophages, lymphocytes, and MHC class I and II cells, were up-regulated early after LPS. The inflammatory response in the brain was further evident by the expression of proinflammatory cytokine transcripts. Some of these, such as IL$1 \beta$, IL- 6 , and TNF- $\alpha$, have previously been shown to be induced in the fetal rat brain after maternal LPS exposure (1).

Interestingly, several genes that are coupled to the transforming growth factor (TGF)- $\beta$ pathway were down-regulated after LPS. TGF- $\beta$ is considered an anti-inflammatory mediator and has, at least in the short term, also been shown to be neuroprotective after HI (16). A negative response in TGF- $\beta$ associated these genes following LPS may therefore have contributed to the enhanced vulnerability of the brain after LPS.

LPS-induced microglial apoptosis has been demonstrated, which was associated with caspase- 3 and 11 activation (17) and we also found regulation of caspase- 3 and caspase-11 transcripts. In support of these findings we found that the caspase-3 activity was increased in the brain following peripheral LPS exposure. In addition, transglutaminase 2, a caspase substrate during apoptosis, which can also alter mitochondrial function and serve as an upstream effector of apoptosis (18) was regulated.

Several genes associated with the TNF- $\alpha$ pathway including Nur77, which prevents TNF- $\alpha$ induced death in macro- 
A

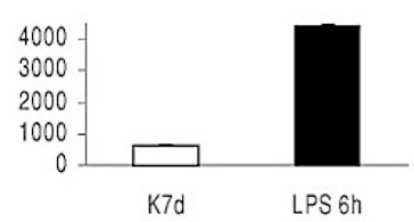

Fold change: 6.8
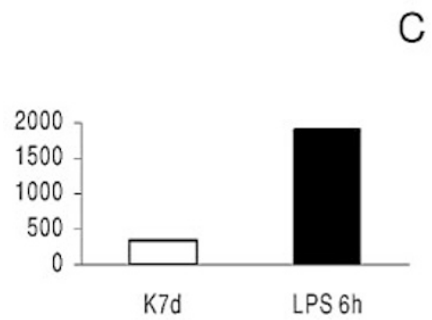

Fold change: 5.7

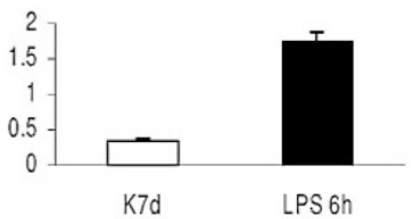

Fold change: 5.0

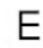

E

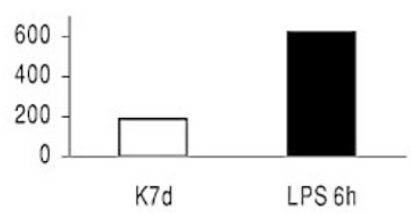

Fold change: 3.2

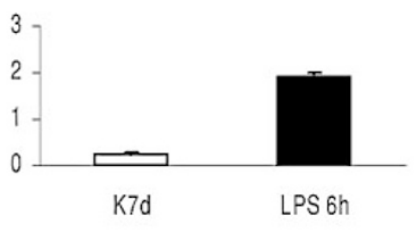

Fold change: 7.5
B Furthermore, IGF-1 is known to trigger Akt activation (25), and in support of these findings, we found a decrease in Akt phosphorylation. The mRNA for Notch 1, which selectively induces extensive apoptosis in progenitor cells, was upregulated on the array. Notch activation in neural progenitor cells leads to elevated levels of nuclear p53 and transcriptional up-regulation of the target genes Bax and Noxa, and the promotion of apoptotic cell death by Notch activation is completely suppressed by p53 deficiency (26). Furthermore, the mRNA for BH3 interacting domain death agonist, which encodes a protein that is a member of the Bcl-2 family and is a mediator of mitochondrial damage via caspase- 8 activation and cytochrome $c$ release, was regulated (27). Taken together, these results indicate involvement of TNF- $\alpha$ and p53 dependent pathways in the immature brain following LPS exposure.

In support of previous studies, the mRNA expression of metallothionein was markedly increased in the brain following LPS (28), which is believed to be a protective response because metallothionein has been shown to reduce brain inflammation, caspase activation, and neurodegeneration (29). Other antiapoptotic genes were also regulated, particularly those associated with the Akt/PI3 K-dependent survival pathway. SGRK is a PI3 K-dependent kinase with structural homology to Akt, which provides cell survival responses to multiple types of stress stimuli (30). PHLDA1 may play an important role in the antiapoptotic effects of IGF-1/Akt pathway because the pleckstrin-homology domain of Akt/protein kinase $\mathrm{B}(\mathrm{Akt} / \mathrm{PKB})$ is activated in response to growth factors (31). PHLDA1 negatively regulates intracellular levels of phosphatidylinositol-3,4,5-trisphosphate in cells and functions as a negative regulator of the PI3 K-Akt/PKB signaling pathway (32). Phosphorylation of PHLDA1 and Akt has also been demonstrated in astrocytes in the rat hippocampus following transient forebrain ischemia (33). The FAIM2 gene codes for a protein that can antagonize Fas-induced cell death (34) and exert neurite growth-promoting action in different neuronal systems (35). Furthermore, resistance of rat cerebellar granule neurons to FasL-induced apoptosis is mediated by PI3 KAKT/PKB-dependent expression of FAIM2 (36). TAX1BP1, which modulates cell cycle progression and apoptosis (37), was also recently shown to be linked to Akt activation, NF-kB translocation, and p53 inhibition (38). These studies suggest that the Akt/PI3 $\mathrm{K}$ pathway is involved in the cerebral responses to LPS, which was further supported by our finding of a decrease in pAkt after LPS exposure.

Taken together, the microarray analysis suggests that both apoptosis-mediated mechanisms and the Akt pathway in the brain may be affected by peripheral LPS exposure. In support of the microarray data, we found evidence of increased caspase-3 activation and reduced phosphorylation of Akt. These results suggest that there may be an increase in cell death mechanisms at the same time as cell survival pathways are inhibited.

In conclusion, we have found a multiplicity of genes regulated in the immature brain, indicating a complex cerebral response to peripheral LPS exposure. The complexity is likely

to be, at least partly, due to cell context and brain region, in a p53-dependent manner (23). Interestingly, concurrenty the IGF-1 gene was down-regulated, which is in agreement, 
which was not investigated in the present study. In addition to the expected inflammatory response, there was regulation of a significant number of cell death-associated genes, which could contribute to the increased vulnerability of the immature brain to HI following LPS exposure. Clearly, to further characterize the cerebral response to LPS, it will be important to study the cellular localization of the expressed genes and also the protein expression.

\section{REFERENCES}

1. Cai Z, Pan ZL, Pang Y, Evans OB, Rhodes PG 2000 Cytokine induction in fetal rat brains and brain injury in neonatal rats after maternal lipopolysaccharide administration. Pediatr Res 47:64-72

2. Mallard C, Welin AK, Peebles D, Hagberg H, Kjellmer I 2003 White matter injury following systemic endotoxemia or asphyxia in the fetal sheep. Neurochem Res 28:215-223

3. Svedin P, Kjellmer I, Welin AK, Blad S, Mallard C 2005 Maturational effects of lipopolysaccharide on white-matter injury in fetal sheep. J Child Neurol 20:960-964

4. Nelson KB, Grether JK 1998 Potentially asphyxiating conditions and spastic cerebral palsy in infants of normal birth weight. Am J Obstet Gynecol 179:507-513

5. Eklind S, Mallard C, Leverin AL, Gilland E, Blomgren K, Mattsby-Baltzer I, Hagberg H 2001 Bacterial endotoxin sensitizes the immature brain to hypoxicischaemic injury. Eur J Neurosci 13:1101-1106

6. Yang L, Sameshima H, Ikeda T, Ikenoue T 2004 Lipopolysaccharide administration enhances hypoxic-ischemic brain damage in newborn rats. J Obstet Gynaecol Res 30:142-147

7. Ikeda T, Yang L, Ikenoue T, Mallard C, Hagberg H 2006 Endotoxin-induced hypoxic-ischemic tolerance is mediated by up-regulation of corticosterone in neonatal rat. Pediatr Res 59:56-60

8. Anthony D, Dempster R, Fearn S, Clements J, Wells G, Perry VH, Walker K 1998 CXC chemokines generate age-related increases in neutrophil-mediated brain inflammation and blood-brain barrier breakdown. Curr Biol 8:923-926

9. Hedtjarn M, Mallard C, Eklind S, Gustafson-Brywe K, Hagberg H 2004 Global gene expression in the immature brain after hypoxia-ischemia. J Cereb Blood Flow Metab 24:1317-1332

10. Hedtjarn M, Mallard C, Hagberg H 2004 Inflammatory gene profiling in the developing mouse brain after hypoxia-ischemia. J Cereb Blood Flow Metab 24:1333-1351

11. Reyes TM, Walker JR, DeCino C, Hogenesch JB, Sawchenko PE 2003 Categorically distinct acute stressors elicit dissimilar transcriptional profiles in the paraventricular nucleus of the hypothalamus. J Neurosci 23:5607-5616

12. Irizarry RA, Bolstad BM, Collin F, Cope LM, Hobbs B, Speed TP 2003 Summaries of Affymetrix GeneChip probe level data. Nucleic Acids Res 31:e15

13. Whitaker JR, Granum PE 1980 An absolute method for protein determination based on difference in absorbance at 235 and $280 \mathrm{~nm}$. Anal Biochem 109:156-159

14. Eklind S, Mallard C, Arvidsson P, Hagberg H 2005 Lipopolysaccharide induces both a primary and a secondary phase of sensitization in the developing rat brain. Pediatr Res 58:112-116

15. Nathan C 2002 Points of control in inflammation. Nature 420:846-852

16. Guan J, Miller OT, Waugh KM, McCarthy DC, Gluckman PD, Gunn AJ 2004 TGF beta-1 and neurological function after hypoxia-ischemia in adult rats. Neuroreport 15:961-964

17. Jung DY, Lee H, Jung BY, Ock J, Lee MS, Lee WH, Suk K 2005 TLR4, but not TLR2, signals autoregulatory apoptosis of cultured microglia: a critical role of IFN-beta as a decision maker. J Immunol 174:6467-6476

18. Piacentini M, Farrace MG, Piredda L, Matarrese P, Ciccosanti F, Falasca L, Rodolfo C, Giammarioli AM, Verderio E, Griffin M, Malorni W 2002 Transglutaminase overexpression sensitizes neuronal cell lines to apoptosis by increasing mitochondrial membrane potential and cellular oxidative stress. J Neurochem 81:1061-1072

19. Suzuki S, Suzuki N, Mirtsos C, Horacek T, Lye E, Noh SK, Ho A, Bouchard D, Mak TW, Yeh WC 2003 Nur77 as a survival factor in tumor necrosis factor signaling. Proc Natl Acad Sci U S A 100:8276-8280
20. Cui X, Imaizumi T, Yoshida H, Tanji K, Matsumiya T, Satoh K 2000 Lipopolysaccharide induces the expression of cellular inhibitor of apoptosis protein-2 in human macrophages. Biochim Biophys Acta 1524:178-182

21. Myokai F, Takashiba S, Lebo R, Amar S 1999 A novel lipopolysaccharide-induced transcription factor regulating tumor necrosis factor alpha gene expression: molecular cloning, sequencing, characterization, and chromosomal assignment. Proc Natl Acad Sci U S A 96:4518-4523

22. Micheau O, Tschopp J 2003 Induction of TNF receptor I-mediated apoptosis via two sequential signaling complexes. Cell 114:181-190

23. Rensink AA, Gellekink H, Otte-Holler I, ten Donkelaar HJ, de Waal RM, Verbeek MM, Kremer B 2002 Expression of the cytokine leukemia inhibitory factor and pro-apoptotic insulin-like growth factor binding protein-3 in Alzheimer's disease. Acta Neuropathol (Berl) 104:525-533

24. Devi GR, Graham DL, Oh Y, Rosenfeld RG 2001 Effect of IGFBP-3 on IGF- and IGF-analogue-induced insulin-like growth factor-I receptor (IGFIR) signalling. Growth Horm IGF Res 11:231-239

25. Brywe KG, Mallard C, Gustavsson M, Hedtjarn M, Leverin AL, Wang X, Blomgren K, Isgaard J, Hagberg H 2005 IGF-I neuroprotection in the immature brain after hypoxia-ischemia, involvement of Akt and GSK3beta? Eur J Neurosci 21:14891502

26. Yang X, Klein R, Tian X, Cheng HT, Kopan R, Shen J 2004 Notch activation induces apoptosis in neural progenitor cells through a p53-dependent pathway. Dev Biol 269:81-94

27. Brustovetsky T, Antonsson B, Jemmerson R, Dubinsky JM, Brustovetsky N 2005 Activation of calcium-independent phospholipase A (iPLA) in brain mitochondria and release of apoptogenic factors by BAX and truncated BID. J Neurochem 94:980-994

28. Miyazaki I, Asanuma M, Higashi Y, Sogawa CA, Tanaka K, Ogawa N 2002 Age-related changes in expression of metallothionein-III in rat brain. Neurosci Res 43:323-333

29. Penkowa M, Florit S, Giralt M, Quintana A, Molinero A, Carrasco J, Hidalgo J 2005 Metallothionein reduces central nervous system inflammation, neurodegeneration, and cell death following kainic acid-induced epileptic seizures. J Neurosci Res 79:522-534

30. Leong ML, Maiyar AC, Kim B, O'Keeffe BA, Firestone GL 2003 Expression of the serum- and glucocorticoid-inducible protein kinase, $\mathrm{Sgk}$, is a cell survival response to multiple types of environmental stress stimuli in mammary epithelial cells. J Biol Chem 278:5871-5882

31. Toyoshima Y, Karas M, Yakar S, Dupont J, Lee H, LeRoith D 2004 TDAG51 mediates the effects of insulin-like growth factor I (IGF-I) on cell survival. J Biol Chem 279:25898-25904

32. Kim S, Domon-Dell C, Kang J, Chung DH, Freund JN, Evers BM 2004 Downregulation of the tumor suppressor PTEN by the tumor necrosis factor-alpha/nuclear factor-kappaB (NF-kappaB)-inducing kinase/NF-kappaB pathway is linked to a default IkappaB-alpha autoregulatory loop. J Biol Chem 279:4285-4291

33. Choi JS, Park HJ, Kim HY, Kim SY, Lee JE, Choi YS, Chun MH, Chung JW, Lee MY 2005 Phosphorylation of PTEN and Akt in astrocytes of the rat hippocampus following transient forebrain ischemia. Cell Tissue Res 319:359-366

34. Somia NV, Schmitt MJ, Vetter DE, Van Antwerp D, Heinemann SF, Verma IM 1999 LFG: an anti-apoptotic gene that provides protection from Fas-mediated cell death. Proc Natl Acad Sci U S A 96:12667-12672

35. Sole C, Dolcet X, Segura MF, Gutierrez H, Diaz-Meco MT, Gozzelino R, Sanchis D, Bayascas JR, Gallego C, Moscat J, Davies AM, Comella JX 2004 The death receptor antagonist FAIM promotes neurite outgrowth by a mechanism that depends on ERK and NF-kappa B signaling. J Cell Biol 167:479-492

36. Beier CP, Wischhusen J, Gleichmann M, Gerhardt E, Pekanovic A, Krueger A, Taylor V, Suter U, Krammer PH, Endres M, Weller M, Schulz JB 2005 FasL (CD95L/APO-1L) resistance of neurons mediated by phosphatidylinositol 3-kinaseAkt/protein kinase B-dependent expression of lifeguard/neuronal membrane protein 35. J Neurosci 25:6765-6774

37. Sieburg M, Tripp A, Ma JW, Feuer G 2004 Human T-cell leukemia virus type (HTLV-1) and HTLV-2 tax oncoproteins modulate cell cycle progression and apoptosis. J Virol 78:10399-10409

38. Jeong SJ, Pise-Masison CA, Radonovich MF, Park HU, Brady JN 2005 Activated AKT regulates NF-kappaB activation, p53 inhibition and cell survival in HTLV-1transformed cells. Oncogene 24:6719-6728 